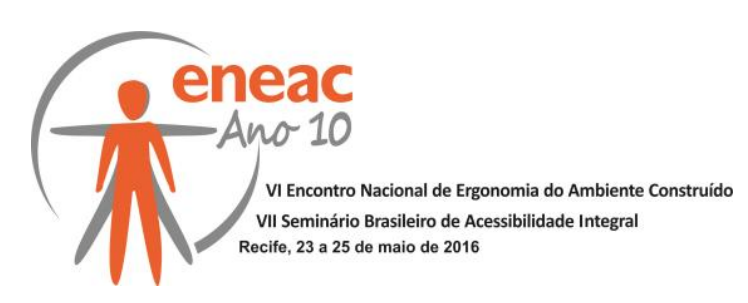

\title{
AVALIAÇÃO ERGONÔMICA DO AMBIENTE CONSTRUÍDO: ESTUDO DE CASO EM UMA LOJA DE CALÇADOS EM OLINDA-PE.
}

\author{
FULGÊNCIO, Vinícius (1); \\ OLIVEIRA, Ana Rosa (2) \\ (1) Instituto Federal da Bahia, Mestre em Desenvolvimento Urbano \\ e-mail:vaf.vinicius@gmail.com \\ (2) Escola Técnica Estadual Professor Agamenon Magalhães, Especialista em Ergonomia \\ e-mail: anarosaal2@ig.com.br
}

\begin{abstract}
RESUMO
O projeto de espaços precisa considerar questões funcionais, estéticas, econômicas e sociais, sempre tendo como foco o usuário. Nesse sentido, a ergonomia apresenta-se como uma área de conhecimento multidisciplinar que contribui para o projeto e avaliação de tarefas, trabalhos, produtos, ambientes e sistemas voltados para as necessidades humanas. Projetar ambientes comerciais é um desafio a parte, pois é preciso pensar em dois usuários com expectativas e necessidades distintas: 0 funcionário e o cliente. Assim, o presente trabalho apresenta a avaliação ergonômica do ambiente construído de uma loja de calçados femininos em Olinda - PE.
\end{abstract}

Palavras chave: ambiente construído; arquitetura de interiores comercial; MEAC; Ergonomia.

\begin{abstract}
The space project needs to consider functional, aesthetic, economic and social issues, always focusing on the user. In this sense, ergonomics presents itself as a multidisciplinary field of knowledge that contributes to the design and evaluation of tasks, jobs, products, environments and systems geared to human needs. Designing commercial environments is challenging part because you need to think of two users with different needs and expectations: the employee and the customer. The present work presents the ergonomic evaluation of the built environment of a women's shoes store in Olinda $P E$.
\end{abstract}

Keywords: building environment; commercial architecture; MEAC; Ergonomics.

\section{INTRODUÇÃO}

É inerente à arquitetura a necessidade de cumprir um programa construtivo para abrigar atividades humanas. A disposição dos espaços determina a maneira como a arquitetura pode promover inciativas, obter respostas e transmitir significado (CHING, 1998). Assim, o projeto de arquitetura precisa cumprir as expectativas do cliente, compilando soluções que considerem os aspectos estéticos, utilitários, estruturais e de custo. (OLIVEIRA; MONT'ALVÃO, 2014).

Um espaço bem projetado precisa garantir qualidade funcional, boa acessibilidade (acessibilidade integral), flexibilidade, ter um arranjo eficiente e compreensível, além de 


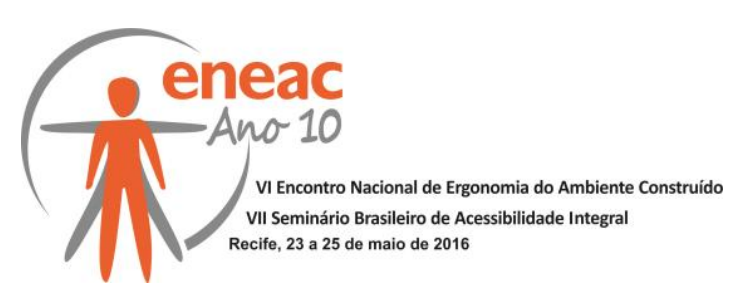

promover a segurança, saúde e bem-estar do usuário. Do contrário, um espaço físico mal projetado, pode apresentar deficiências que influenciam negativamente na qualidade de vida do homem (VOORDT; WEGEN, 2005).

Desta forma, um projeto com olhar ergonômico precisa antever sua utilização, conjugar condicionantes físicos, cognitivos, antropométricos, da acessibilidade, psico-sociais e culturais, objetivando identificar variáveis passíveis de não atendimento pelo produto proposto (VILLAROUCO, 2002).

A Ergonomia configura-se como importante ferramenta no entendimento do grande sistema que compõe o ambiente construído, considerando conceitos relativos ao ambiente arquitetônico, desenvolvimento de atividades, bem como a adequação do espaço às capacidades, habilidades e limitações humanas. Trata-se de um estudo dialético que foca na relação entre humano-ambiente-atividade (MONT'ALVÃO, 2011).

É importante destacar que as normativas relativas ao conforto acústico (NBR 10152), acessibilidade (NBR 9050) e dimensionamento mínimo de ambientes (Código de obras municipal) são diretrizes que nem sempre atendem às necessidades específicas dos usuários. Nesse sentido, Parsons (2005) faz uma reflexão crítica quanto aos estudos da ergonomia que consideram o ambiente apenas do ponto de vista técnico. Assim, é fundamental a avaliação do espaço arquitetônico e suas interfaces com a usabilidade e adequação ambiental, psicologia ambiental, ergonomia cognitiva e física.

O presente trabalho tem como objetivo realizar uma avaliação ergonômica do ambiente construído de uma loja de calçados localizada em Olinda - PE. Gurgel (2014) aponta que a complexidade do projeto de arquitetura comercial está em atender a demanda de dois públicos distintos: o trabalhador (usuário permanente) e o cliente (usuário esporádico). Além disso o projeto precisa considerar o contexto socioeconômico, a imagem da empresa, o público alvo e sua estrutura de trabalho.

A escolha do ambiente está relacionada a importância do setor calçadista na economia do Brasil que, segundo Mota et al (2015), vem apresentando um crescimento médio maior que o Produto Interno Bruto (PIB) nacional, apesar do cenário econômico recente. Considerando essa importância econômica é preciso pensar em ambientes adequados aos vendedores e aos clientes, contribuindo para o crescimento desse setor.

\section{METODOLOGIA}

O desenvolvimento deste trabalho foi realizado por meio da aplicação da Metodologia Ergonômica para o Ambiente Construído - MEAC (VILLAROUCO, 2009). Esta metodologia consiste em uma avaliação ergonômica desenvolvida em duas etapas gerais de coleta de dados em pesquisa de campo: a primeira de ordem física e a segunda de ordem perceptiva.

A fase física divide-se em três partes:

Análise Global do Ambiente: busca entender o ambiente e as atividades nele realizadas, além de caracterizar os problemas e demandas gerais, que apontem a necessidade de intervenção.

Configuração Ambiental: realiza-se o levantamento de todos os dados do ambiente, tais como dimensionamento, iluminação, ventilação, ruído, temperatura, layout, deslocamentos, materiais de revestimentos e condições de acessibilidade.

Ambiente em uso: visa identificar a usabilidade do ambiente, ou seja, o quão facilitador ou dificultador ele representa ao desenvolvimento das atividades que abriga.

A fase perceptiva objetiva investigar as expectativas e impressões dos usuários em relação ao ambiente. Para tanto, utiliza-se os conhecimentos relativos à psicologia ambiental e suas ferramentas que auxiliam na identificação de variáveis de natureza cognitiva. Aponta 


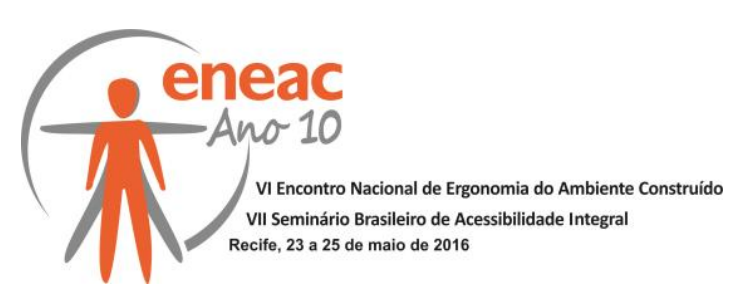

Andreto (2005) que tais ferramentas facilitam ao pesquisador perceber dos usuários quais aspectos relacionados ao espaço de trabalho estão ligados às questões motivacionais.

A ferramenta escolhida para o presente estudo foi a Constelação de Atributos que, a partir de duas perguntas relativas ao ambiente ideal e ao ambiente real, identifica por meio da representação gráfica dos atributos (reais e imaginários) às impressões que o usuário possui do espaço utilizado.

Por fim, faz-se uma compilação dos dados coletados e, após uma avaliação sistêmica, desenvolver um Diagnóstico Ergonômico que considera os aspectos relacionados às questões físicas, estéticas, organizacionais, cognitivas, de conforto ambiental, de mobiliário, de segurança e de acessibilidade. Por fim, faz-se às Recomendações Ergonômicas no intuito de contribuir para a melhoria do ambiente.

\subsection{Análise Global do Ambiente}

O ambiente a ser avaliado nesse trabalho é uma loja de calçados femininos localizada em um empresarial de pequeno porte no bairro de Casa Caiada, Olinda - PE. A loja possui duas funcionárias que atuam no atendimento, na armazenagem e no caixa, sendo que uma delas é a proprietária do estabelecimento. O horário de atendimento vai de segunda a sexta das $9 \mathrm{~h}$ às $17 \mathrm{~h}$ e aos sábados das $9 \mathrm{~h}$ às $13 \mathrm{~h}$. Os produtos comercializados são calçados, bolsas e acessórios femininos voltados para um público de idade adulta, sendo mais presentes clientes entre 25 e 40 anos.

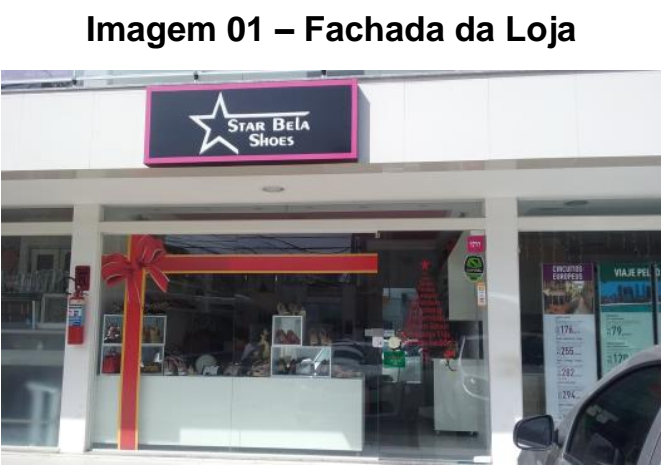

Com suas atividades iniciadas em setembro de 2015, a proprietária relata que seu intuito é proporcionar um ambiente agradável para seus clientes e comercializar produtos com preços acessíveis, mas também com marcas de maior valor agregado, voltada para a classe média de Olinda. A proprietária relatou que utilizará as recomendações desse trabalho para seu novo estabelecimento, pois irá expandir a marca com um espaço no Patteo Olinda Shopping, com inauguração prevista para 2017.

\subsection{Configuração Ambiental}

\subsubsection{Dimensionamento}

A loja possui uma área útil total de $18,87 \mathrm{~m}^{2}$ (ver Imagem 02) que contempla um único vão para área de expositores, vitrine, armazenagem, balcão de atendimento, assentos para clientes, bancada de apoio para cafeteira e água, além de um lavabo fechado com 2 peças (bacia sanitária e pia).

Sua fachada está voltada para o sul e seu acesso se dá por uma porta de $90 \mathrm{~cm}$ de vão livre, não havendo área específica para descarga de mercadoria. Tanto a área de circulação dos clientes como a área de funcionários possuem uma largura média de $70 \mathrm{~cm}$. O lavabo possui $1,94 \mathrm{~m}^{2}$, sendo $1,23 \mathrm{~m}$ de largura e 1,63 de comprimento. 


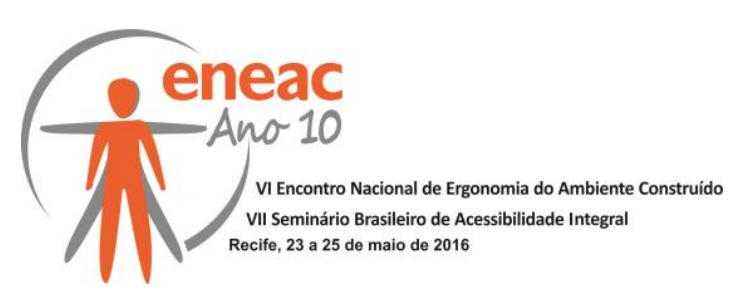

Os expositores e a vitrine estão dispostos na zona periférica da planta, ou seja, juntas às paredes. A área administrativa é separada por um balcão de $50 \mathrm{~cm}$ de largura e $1 \mathrm{~m}$ de altura.

\section{Imagem 02 - Planta baixa da loja com zoneamento.}

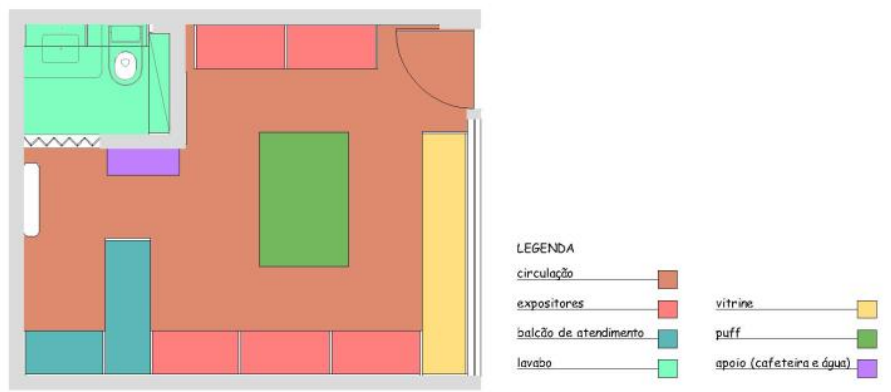

Analisando a circulação do ponto de vista experiencial, Gurgel (2014) classifica, a partir da disposição do layout, o fluxo dos usuários de duas maneiras: natural e forçada. A natural é aquela em que o usuário caminha livremente sem receio do bloqueio por algum tipo de obstáculo e sem nenhum tipo de indução. Por sua vez, a forçada é aquela em que o consumidor é condicionado a fazer determinado percurso devido a inserção de alguns mobiliários, dessa maneira o usuário caminha mais atento buscando referências sobre a direção que deve seguir.

Diante disso, é possível afirmar que a circulação da loja é forçada, pois o puff no centro da área de circulação dos clientes os conduz a caminhar próximos aos expositores. Imaginemos, por exemplo, que um cliente vai à loja realizar apenas uma troca, como ele não tem um caminho direto ao balcão de atendimento é preciso passar pela circulação que é próxima aos expositores, aumentando as chances de venda. Trata-se de uma estratégia para forçar o cliente a caminhar por setores diferentes, mesmo que ele não deseje faze-lo (GURGEL, 2014).

\subsubsection{Conforto Ambiental}

\section{LUMÍNICO}

Para análise de conforto lumínico, foram realizadas medições com o aplicativo Luxímetro Ourolux, para celular, pela manhã (10h) e a tarde (14h). Os resultados foram comparados com os níveis prescritos pela norma de lluminância de Interiores NBR 5413 (ABNT, 1992). Para o interior da loja em geral são indicados no mínimo $300 l u x$ e no máximo 750 lux, enquanto que a para a vitrine são indicados no mínimo 750 lux e no máximo 1500 lux. É importante salientar que em alguns pontos de medição a iluminação era exclusivamente natural, em outros exclusivamente artificial e em outros com ambas as fontes. Como o objetivo é fazer as medições com o ambiente em uso, não houve interferência dos pesquisadores.

\begin{tabular}{|c|c|c|c|c|}
\hline PONTO & LUX (manhã) & LUX (tarde) & NBR 5413 & LOCAL \\
\hline $\mathbf{0 1}$ & 360 & 332 & $300-500-750$ lux & Balcão de atendimento \\
\hline $\mathbf{0 2}$ & 349 & 261 & $300-500-750$ lux & Balcão de atendimento (livro-caixa) \\
\hline $\mathbf{0 3}$ & 840 & 1080 & $300-500-750$ lux & Expositor Leste \\
\hline $\mathbf{0 4}$ & 557 & 775 & $300-500-750$ lux & Expositor Oeste \\
\hline $\mathbf{0 5}$ & 3118 & 4.100 & $750-1000-1500$ lux & Vitrine \\
\hline $\mathbf{0 6}$ & 452 & 452 & $300-500-750$ lux & Lavabo \\
\hline
\end{tabular}




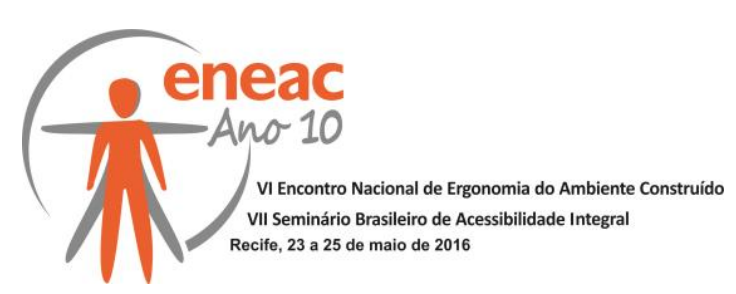

Observa-se que parte do balcão de atendimento, onde fica o livro-caixa, a iluminação está abaixo do recomendado no turno da tarde. Trata-se de um local cuja atividade está diretamente ligada às questões financeiras da loja, sendo necessária a iluminação adequada para as atividades de leitura, conferencia e escrita.

O expositor leste apresentou uma quantidade de lux muito acima do recomendado pela norma nos dois turnos, em certa medida isso ocorreu devido à proximidade da porta de acesso toda em vidro. Já o expositor oeste apresentou 25 lux acima do recomendado no período da tarde.

Por fim, a vitrine apresentou, em ambos os turnos, taxas bem acima do recomendado. A norma admite taxas que variam de 3000 lux a 7500lux em vitrines com iluminação concentrada, mas não é o caso dessa. Apesar da sombra criada pela circulação do andar superior, a vitrine recebe luz natural boa parte durante o dia e isso influencia diretamente nas taxas encontradas.

\section{ACÚSTICO}

As condições de conforto acústico foram analisadas a partir das medições de ruído interno nos turnos da manhã (10h) e da tarde (14h) com o aplicativo Sound Meter, para celular. A NBR 10.152 (ABNT, 2000) não possui indicações específicas para lojas comerciais e, para fornecer parâmetros ao trabalho, foram consideradas as seguintes referências: a indicação de $65 \mathrm{~dB}$, disposta na NR 17, como ruído máximo permitido para áreas de trabalho não contempladas na NBR 10152; ruído moderado como àquele de valores entre $40 \mathrm{~dB}$ e $50 \mathrm{~dB}$ (NEUFERT, 1998); e a adoção das taxas estabelecidas na NBR 10.152 para restaurantes (40-50 dB), considerando que, apesar das particularidades, também é um estabelecimento comercial. Os resultados encontrados foram comparados com e dispostos na tabela abaixo.

\begin{tabular}{|c|c|c|c|c|c|}
\hline PONTO & $\begin{array}{c}\text { RUÍDO } \\
\text { (manhã) }\end{array}$ & $\begin{array}{l}\text { RuÍDO } \\
\text { (tarde) }\end{array}$ & NR 17 & NBR 10.152 & LOCAL \\
\hline 01 & $27 \mathrm{~dB}$ & $73 \mathrm{~dB}$ & $65 \mathrm{~dB}$ & $40-50 \mathrm{~dB}$ & Balcão de atendimento \\
\hline 02 & $24 \mathrm{~dB}$ & $66 \mathrm{~dB}$ & $65 \mathrm{~dB}$ & $40-50 \mathrm{~dB}$ & Balcão de atendimento (livro-caixa) \\
\hline 03 & $24 \mathrm{~dB}$ & $55 \mathrm{~dB}$ & $65 \mathrm{~dB}$ & $40-50 \mathrm{~dB}$ & Expositor Leste \\
\hline 04 & $22 \mathrm{~dB}$ & $56 \mathrm{~dB}$ & $65 \mathrm{~dB}$ & $40-50 \mathrm{~dB}$ & Expositor Oeste \\
\hline 05 & $31 \mathrm{~dB}$ & $72 \mathrm{~dB}$ & $65 \mathrm{~dB}$ & $40-50 \mathrm{~dB}$ & Vitrine \\
\hline
\end{tabular}

Considerando as disposições da NBR 10.152, durante o turno da manhã os índices apresentaram-se abaixo dos $40 \mathrm{~dB}$, enquanto no turno da tarde as medições em todos os pontos foram superiores a $50 \mathrm{~dB}$, isso porque durante a tarde houve movimentação de clientes, enquanto pela manhã só estava uma vendedora. Percebe-se também que as medições no ponto 05 (Vitrine) foram consideravelmente mais elevados que a média, tal fato se deu pela proximidade da vitrine com a rua e a área de estacionamento da galeria.

Por outro lado, se considerarmos os $65 \mathrm{~dB}$ indicados pela NR 17, apenas o balcão de atendimento e a vitrine estão acima dos decibéis recomendados. É natural que o balcão de atendimento apresente tal resultado já que é nesse espaço que as transações comerciais são finalizadas, enquanto que a vitrine é pela proximidade com a rua, razão já citada anteriormente.

Controlar o ruído em ambientes empresariais é um grande desafio, mas que pode ser atenuado com materiais macios e porosos, em especial nas maiores superfícies do ambiente: o piso e o teto. Forros acústicos são bastante empregados e muitos são trabalhados esteticamente com geometrias variadas, enquanto o piso pode ser trabalhado com carpete e, para zonas mais úmidas, tapetes são uma alternativa, lembrando do cuidado que se deve ter para evitar acidentes como escorregões (GURGEL, 2014). 


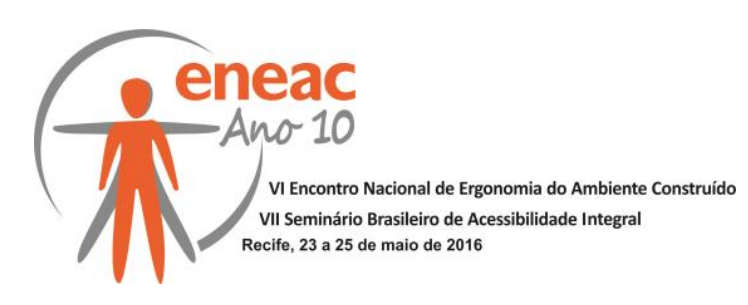

\section{TÉRMICO}

As condições de conforto acústico foram analisadas a partir de medições nos turnos da manhã (10h) e da tarde (14h) com o aplicativo Smart Thermometer, para celular. Como o ambiente possui uma dimensão pequena houve pouca variação de temperatura. Durante o turno da manhã a temperatura média foi de $26^{\circ} \mathrm{C}$, chegando a $30^{\circ} \mathrm{C}$ na área da vitrine. A tarde a temperatura média da loja foi de $28^{\circ} \mathrm{C}$, chegando a $33^{\circ} \mathrm{C}$ na área da vitrine.

A NR 17 recomenda a temperatura entre $20^{\circ} \mathrm{C}$ e $23^{\circ} \mathrm{C}$ para locais de trabalho onde são executadas atividades que exijam solicitação intelectual e atenção constantes. Diante disso, é possível aferir que a loja não está dentro do indicado, apesar da refrigeração artificial ser constantemente utilizada no estabelecimento.

\subsubsection{Materiais de Revestimento}

Os materiais de revestimento num projeto de arquitetura de interiores têm duas principais importâncias: a primeira de caráter funcional e a segunda de caráter estético. É preciso que os materiais tenham durabilidade, resistência, fácil manutenção, sejam antiderrapantes e contribuam para o conforto térmico e acústico. Também é necessário que os materiais passem a mensagem desejada pela empresa, pois as cores, texturas, padrões e acabamentos possuem simbolismos que geram interpretações e estímulos (GURGEL, 2014).

A fachada da loja é toda em vidro, tanto a vitrine como a porta de acesso, conforme pode ser verificado na Imagem 01. Internamente (Ver Imagem 03), as cores predominantes são branco, magenta e preto em conformidade com a identidade visual da marca. $\mathrm{O}$ tom branco predominante torna o espaço mais amplo, mas por outro lado reflete bastante a luz.

O piso possui revestimento cerâmico na cor branca em todo o vão e há um tapete impermeável, antiderrapante e antialérgico de cor prata no centro da loja. As paredes são revestidas com tinta fosca na cor branca, exceto um pequeno trecho na área do espelho que possui textura em papel de parede. O teto possui gamelas e roda teto em gesso na cor branca e o centro revestido com tinta fosca na cor magenta.

O mobiliário que compõe os expositores, balcão de atendimento, apoio para café e vitrine são todos em fórmica branca, exceto as portas do estoque abaixo os expositores que são na cor preta. No centro da loja há um grande puff capitonê, de cor magenta e textura aveludada que serve de assento para os clientes experimentarem os calçados.

\section{Imagem 03 - Área interna da Loja (materiais de acabamento).}

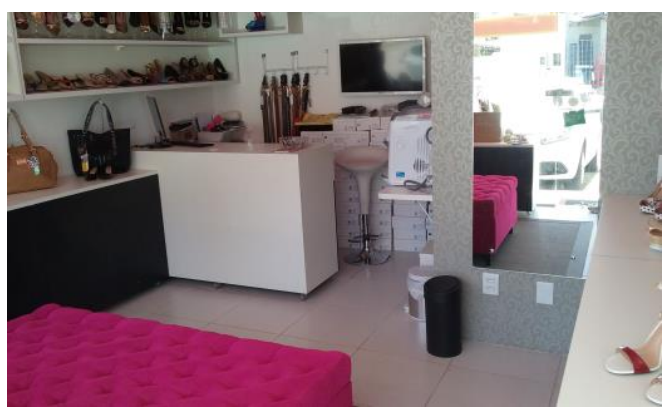

Quanto as condições de conservação dos materiais de revestimento, verificou-se que em alguns expositores a formica está descolando e que parte do piso próximo a entrada está com cola aderida ao substrato cerâmico. 


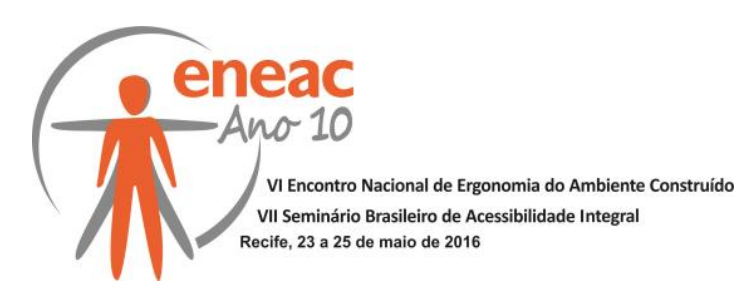

\subsubsection{Acessibilidade}

O primeiro percurso para o acesso à loja é realizado pela circulação comum da galeria que possui um desnível de $50 \mathrm{~cm}$ e não possui rampas de acesso. Já o acesso à loja é feito por uma porta de vão livre de $90 \mathrm{~cm}$ e possui um desnível de $2 \mathrm{~cm}$ em relação a circulação comum da galeria. De acordo com a NBR № 9050 de 2015 desníveis acima de $2 \mathrm{~cm}$ devem ser considerados como degraus e associados a rampas ou equipamentos eletromecânicos de transporte vertical. Já os desníveis entre $0,5 \mathrm{~cm}$ e $2 \mathrm{~cm}$ devem possuir uma inclinação de no máximo $50 \%$. Tanto o acesso da galeria como o acesso da loja não estão de acordo com a norma e dificultam o acesso do usuário cadeirante. Além disso há um tapete na entrada da loja que pode dificultar o acesso ao cadeirante.

Internamente, de acordo com a NBR 9050 (ABNT, 2015), a circulação seria suficiente para pessoas sem órtese ou cadeira de rodas $(60 \mathrm{~cm})$, tanto na área destinada aos clientes $(70 \mathrm{~cm})$ como na área dos funcionários $(70 \mathrm{~cm})$. Considerando o mobiliário como obstáculo isolado ou como um espaço contínuo (deslocamento em linha reta), em ambos os casos, o dimensionamento da área de circulação não contempla o usuário cadeirante, pois deveria ser de $90 \mathrm{~cm}$.

Em relação ao lavabo verificou-se que é apenas para uso dos funcionários, os clientes utilizam o banheiro comum da galeria. Apesar de não haver funcionários com algum tipo deficiência, o lavabo não é acessível, tanto pela ausência de barras de apoio como pela dimensão. Considerando as disposições da NBR 9050, para pessoa sem órtese ou cadeira de rodas, o banheiro seria satisfatório, pois a largura média de sua circulação interna é de 0,61cm. Já Neufert (1998), recomenda que a largura útil de circulação interna de sanitários com 2 peças deve ser de $75 \mathrm{~cm}$, também considerando apenas usuários sem órtese ou cadeira de rodas.

Verificou-se que não há presença de piso tátil ou qualquer sinalização em braile, tanto na área comum da galeria como na área interna da loja. Considerando as questões anteriormente levantadas, o presente objeto de estudo possui dimensões satisfatórias para pessoas sem deficiências, mas não se configura como um ambiente acessível.

\subsection{AVALIAÇÃO DO AMBIENTE EM USO}

O fluxo mais intenso da loja encontra-se no percurso que vai da entrada, passando pelos expositores leste, contornando o puff e chegando ao balcão de atendimento. O fluxo médio está na área da vitrine e dos expositores oeste e o menor fluxo encontra-se na área administrativa (Ver Imagem 05). O maior fluxo se dá pelo fato de que neste percurso passam clientes, funcionários e fornecedores, o fluxo médio fica restrito aos clientes e o funcionário, já o fluxo menor está na área de atendimento que é limitado aos funcionários.

Imagem 05 - Planta baixa com fluxos.

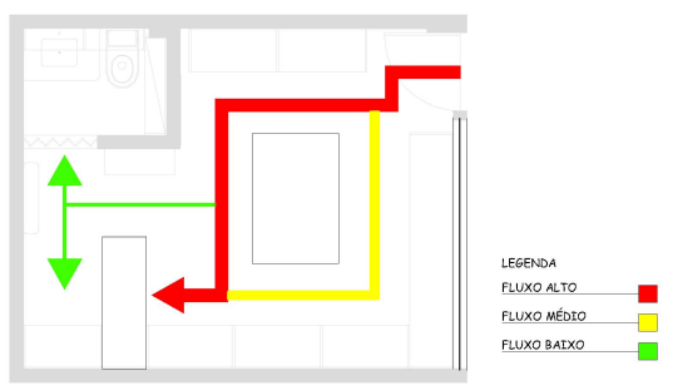

Observando o ambiente em uso pelos usuários, verificou-se problemas no alcance de alguns produtos localizados nas prateleiras mais altas (Ver Imagem 06). Para Gurgel (2014), prateleiras em ambientes comerciais devem ter no máximo 1,95 m (sem campo visual) e 


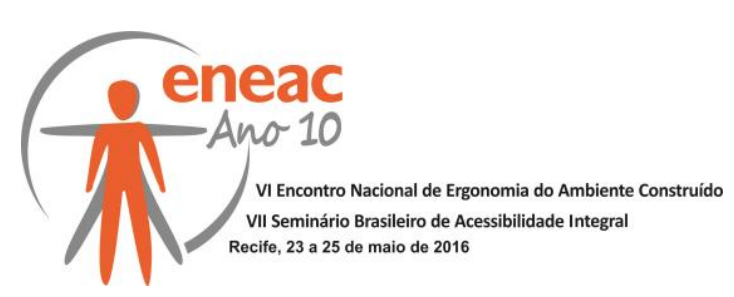

1,50m (com alcance visual). Já Panero e Zelnik (1996) apontam que as alturas máximas para prateleiras que permitam o alcance sem desconforto são de 1,82m (para homens) e $1,75 \mathrm{~m}$ (para mulheres). A prateleira mais alta está a 1,90m do piso, sendo compatível apenas com a indicação de Gurgel (2014). A penúltima prateleira possui uma altura de 1,60m, sendo compatível com as indicações de Gurgel e de Panero e Zelkin (1996), considerando que só há funcionárias.

Por sua vez, a NBR 9050 de 2015 indica uma altura máxima de 1,55m para um alcance confortável. Assim, ambas estão fora dos padrões determinados pela NBR 9050. Uma das funcionárias relatou que, quando o cliente é alto, e precisa buscar algum produto na última prateleira (de altura $1,90 \mathrm{~m}$ ) costuma pedir ao cliente que pegue o produto. Ela ainda relatou que havia uma escada para essas ocasiões, mas que foi retirada da loja com o aumento de caixas de sapato estocadas na área administrativa.

\section{Imagem 06 - Ambiente em uso: alcance das prateleiras.}

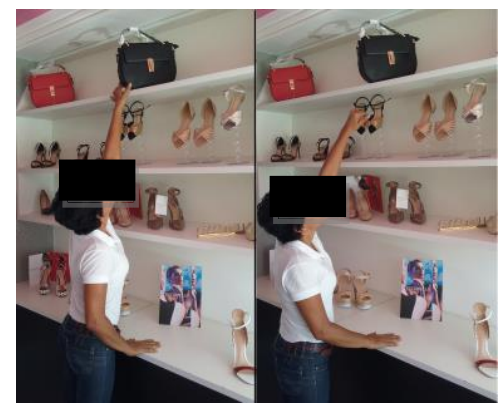

Para um uso confortável de armários baixos com portas é preciso, no mínimo, uma área livre de $76 \mathrm{~cm}$, considerando que o usuário precisa se agachar para ter acesso aos produtos guardados no móvel em questão (PANERO; ZELKIN, 1996). A folhas das portas dos armários possuem $0,50 \mathrm{~cm}$ e se projetam numa área livre de $70 \mathrm{~cm}$, estando fora das medidas indicadas. No entanto, a partir da análise do ambiente em uso, verificou-se uma utilização satisfatória do mobiliário e sem queixas dos usuários (Ver Imagem 07).

\section{Imagem 07 - Ambiente em uso: armários de estoque.}

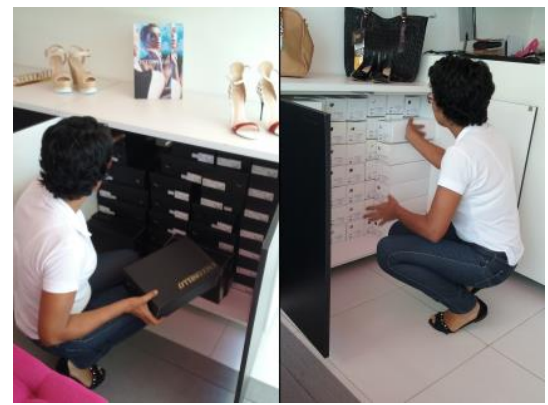

Um grave problema levantado em campo foi a estocagem de produtos na área administrativa que reduz a área de circulação e permanência, dificultando as atividades exercidas no local (Ver Imagem 08). O problema se estende para o lavabo, pois há caixas também estocadas no ambiente com dimensões mínimas. Há, também, caixas na bancada da pia, objetos pessoais dos funcionários e materiais de limpeza armazenados de forma inadequada.

A proprietária relatou que, apesar da grande quantidade de armários para armazenagem, não há espaço suficiente para as caixas. Ainda segundo a dona do estabelecimento, o problema poderia ser resolvido com um mezanino. No entanto, esse tipo de estrutura deveria ter sido projetado pelos construtores do empresarial. 


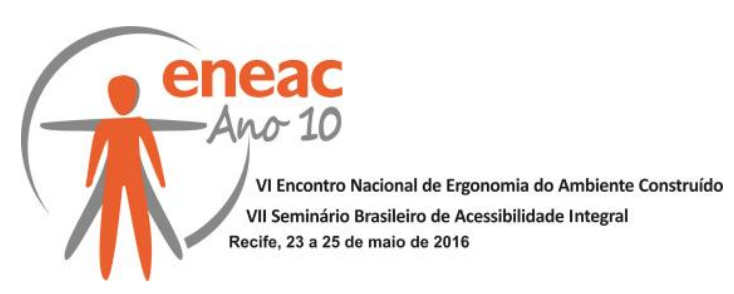

Imagem 08 - Ambiente em uso: estoque em local inadequado (área administrativa).

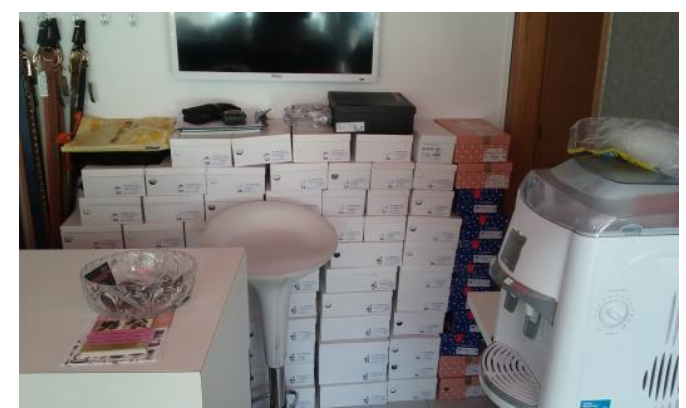

Por fim, verificou-se a inadequação do balcão de atendimento para as atividades realizadas ali exercidas. Apesar do assento ter altura compatível com a do balcão não há espaço para a acomodação das pernas, dificultando algumas tarefas de escrita ou no computador. Já se o funcionário estiver em pé durante o atendimento, o balcão apresenta dimensionamento adequado (Ver Imagem 10).

Imagem 10 - Ambiente em uso: balcão de atendimento (área administrativa).

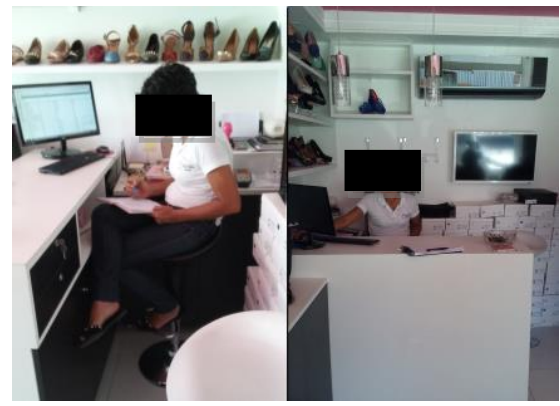

\subsection{AVALIAÇÃO DA PERCEPÇÃO DO USUÁRIO}

Para esta etapa foi utilizada a ferramenta de psicologia ambiental denominada Constelação de Atributos, desenvolvida por Moles (1968) e utilizada amplamente pelos pesquisadores e profissionais que trabalham com o projeto do espaço. Tal ferramenta permite compreender a consciência psicológica do usuário em relação ao espaço que ocupa, trabalhando com uma análise das associações espontâneas de ideias a partir de imagens utilizadas pelo homem para determinar o ambiente em que vivem.

A Constelação de Atributos analisa o ambiente construído a partir de duas dimensões: a conceituação do espaço ideal e outra do espaço real. A primeira está voltada a ideias associadas a características espontâneas, enquanto a última está ligada a associação de ideias a partir de características induzidas.

Como o ambiente em estudo atende, fundamentalmente, aos funcionários e aos clientes, optou-se por desenvolver questionários separados para cada um desses usuários. Assim, foram desenvolvidas 4 Constelações de Atributos, duas imaginárias e duas reais, cada uma específica para um tipo de usuário. Para o primeiro grupo, entrevistou-se a única funcionária da loja e a proprietária, pois ela também atua como tal. Já o grupo dos clientes, entrevistouse apenas 3 , os quais se dispuseram a responder o questionário dentro da movimentação do dia.

Para a Constelação de Atributos Imaginária, de ambos os grupos, foi feita a seguinte pergunta: Quando você pensa em uma loja de sapatos e acessórios, de uma maneira geral, que ideias ou imagens the vêm à mente?'. Já para a Constelação de Atributos real, de ambos os grupos, foi feita a seguinte pergunta: "Quando você pensa nessa loja de sapatos e acessórios, que ideias ou imagens Ihe vêm à mente?". 


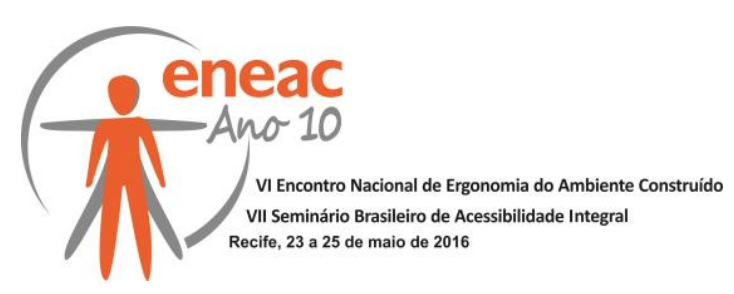

A Imagem 11 apresenta a Constelação de Atributos Imaginária e Real dos funcionários. Para esses usuários os três principais elementos que uma loja de sapatos e acessórios deve ter são os seguintes: copa, lavabo grande e almoxarifado. De forma menos citada, a idealização de um espaço físico maior, bem como a possibilidade de moveis maiores. Em relação ao ambiente real os atributos mais citados são os seguintes: ambiente agradável, lavabo pequeno e a inexistência de almoxarifado. Em segundo plano, mas relacionado ao almoxarifado, foram citadas a presença de muitas caixas fora do estoque, o pouco espaço e a necessidade de mais móveis.

Durante essa etapa da entrevista percebeu-se que, para os funcionários, boa parte dos problemas existentes no ambiente estão relacionados a falta de espaço, com a inexistência de copa para refeições e de um lavabo mais confortável, bem como pela presença de caixas em locais impróprios devido a inexistência de um almoxarifado ou de mais móveis para armazenagem. Tais questões esbarram na falta de espaço presente em todos os módulos das lojas do empresarial, exceto àquelas lojas que foram constituídas por dois módulos através de reformas.

Imagem 11 - Constelação de Atributos (ideal e real): funcionários.
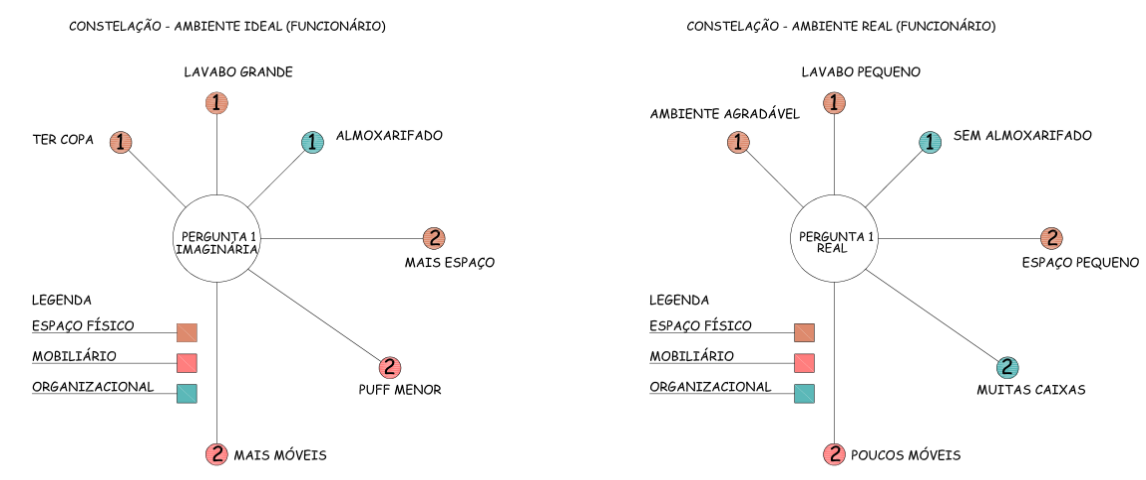

A loja de calçados e acessórios ideal para os clientes deve ter um ambiente confortável e um bom atendimento. Em segundo plano foram citados o bom preço e produto e, em último plano uma boa área de estacionamento. Em relação ao ambiente real, os clientes apontaram três principais características do estabelecimento em estudo: o bom atendimento, o ambiente agradável e o preço acessível. Em segundo plano foi citado a boa qualidade do produto. Aparentemente essas qualidades são os principais motivos que incentivam esses compradores a consumirem os produtos da loja.

Imagem 12 - Constelação de Atributos (ideal e real): clientes.
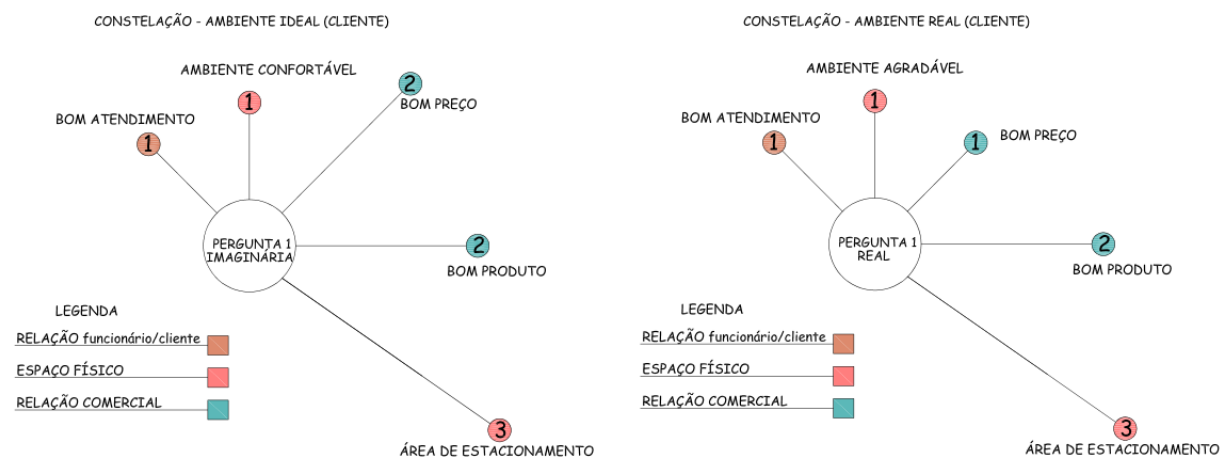

A partir das respostas obtidas é possível aferir a importância do desenvolvimento de questionários separados para os dois tipos de usuários do ambiente. Apesar de terem sido feitas as mesmas perguntas, os atributos relacionados foram, em sua maioria, distintos. $O$ cliente tem expectativas e percepções do ambiente diferentes dos funcionários e vice-versa. 


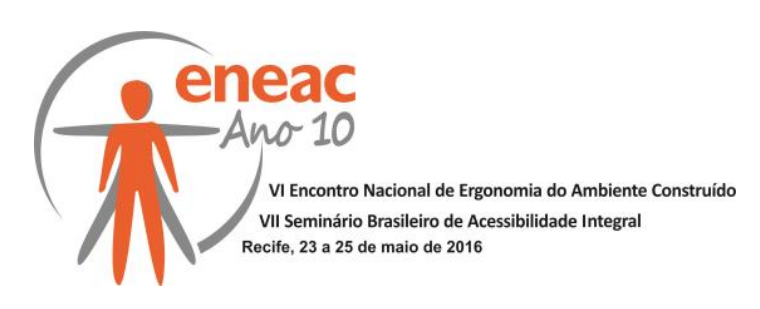

Assim, para um melhor desempenho da avaliação é necessário observar o mesmo espaço a partir das diversas óticas.

\section{CONSIDERAÇÕES FINAIS}

Inicialmente é preciso dizer que, do ponto de vista dimensional, $18 \mathrm{~m}^{2}$ não satisfazem as exigências da NBR 9050 quanto às circulações. No entanto, a área de circulação dos clientes poderia ser otimizada com um puff de menor dimensão. O lavabo, além de não ser acessível, é subdimensionado, requerendo uma intervenção maior. Além da questão dimensional, o estudo de caso não satisfaz outras exigências da NBR 9050 como piso tátil, altura das prateleiras e o espaço para abertura das portas dos armários. Em relação a essa última exigência, mesmo com a alteração do puff não seria possível cumprir com a norma, pois trata-se de uma limitação espacial do módulo da loja.

Em relação ao conforto ambiental é possível dizer que os problemas são, em geral, contornáveis. O problema de iluminação insuficiente na área do livro caixa poderia ser resolvido acionando a luz artificial existente. $\mathrm{Na}$ área da vitrine poderia ser aplicada uma película de proteção UV, mas com cuidado para não interferir na apresentação dos produtos. Considerando a NR 17 o conforto acústico não apresentou problemas graves, mas considerando a NBR 10.152 seria recomendado o uso de algum material absorvente no teto. Já o conforto térmico mostrou-se inadequado, mas que pode ser resolvido com uma melhor regulação da refrigeração artificial em conjunto com a película UV recomendada.

Quanto ao mobiliário recomenda-se regular a altura das prateleiras para àquela indicada pela NBR 9050, bem como a abertura de uma área para as pernas embaixo do balcão de atendimento. Recomenda-se também que sejam feitos os reparos para a conservação da fórmica dos móveis e da cerâmica do piso.

Do ponto de vista organizacional é urgente a necessidade de uma área maior para o estoque. É preciso retirar as caixas que se encontram na área administrativa, bem como àquelas que estão no lavabo. Tais medidas não resolvem, mas atenuam o problema dimensional da loja. Uma área para as refeições dos funcionários também é urgente, mas o espaço da loja não permite alocar tal ambiente.

De maneira geral, percebe-se uma inadequação da área útil da loja com as demandas dos usuários, do programa de necessidades e das exigências postas pelas normas regulamentadores específicas. Assim, é importante levantar uma nova discussão acerca do dimensionamento mínimo de áreas comerciais que considerem não só as normas, mas a dinâmica e o mobiliário desses ambientes de trabalho.

\section{REFERÊNCIAS BIBLIOGRÁFICAS}

ASSOCIAÇÃO BRASILEIRA DE NORMAS TÉCNICAS. NBR 10.152: Nível de ruído para conforto acústico. Rio de Janeiro, 2000.

ASSOCIAÇÃO BRASILEIRA DE NORMAS TÉCNICAS. NBR 5.413: lluminância de interiores. Rio de Janeiro, 1992.

ASSOCIAÇÃO BRASILEIRA DE NORMAS TÉCNICAS. NBR 9.050: Acessibilidade a edificações, espaço, mobiliário e equipamentos urbanos. Rio de Janeiro, 2015.

CHING, Francis D. K.. Arquitetura, Forma, Espaço e Ordem. São Paulo: Martins Fontes, 1998.

GURGEL, M. Projetando espaços: guía de arquitetura de interiores para áreas comerciais. São Paulo: Editora Senac São Paulo, 2014. 


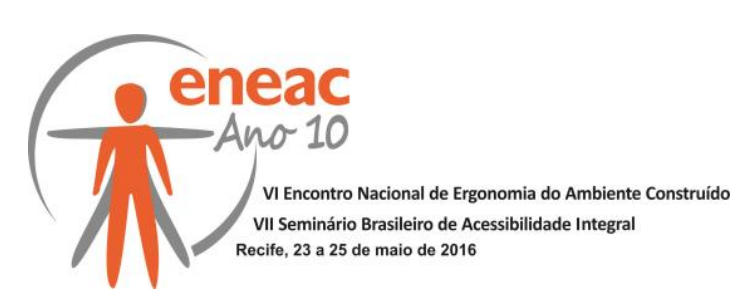

MINISTÉRIO DO TRABALHO. NR 17: Segurança e Medicina do trabalho. São Paulo: Editora Atlas, 1996.

MONT ÀLVÃO, C. A ergonomia do ambiente construido no Brasil. In: MONT'ALVÃO, C.; VILLAROUCO, V.(org) Um novo olhar para o projeto: a ergonomia no ambiente construido. Rio de Janeiro: 2AB, 2011.

MOTA, et al. Avaliação ergonômica: aplicação do método OWAS em uma loja de calçados. In: XXXV Encontro Nacional de Engenharia de Produção. Fortaleza, 2015.

NEUFERT, E. A arte de projetar em arquitetura. São Paulo: G.Gili, 1998.

OLIVEIRA, Gilberto; MONT'ALVÃO, Cláudia. Método e metodologia projetual: o que dizem os profissionais de design de interiores e arquitetos sobre o processo?. In: Cláudia Mont'Alvão e Vilma Villarouco (Orgs.). Um novo olhar para o projeto: a ergonomia no ambiente construído - Recife: Editora UFPE, 2014. 247p.

PANERO, J; ZELNIK, M. Las Ddmensiones humanas em los espacios Interiores. México D.F: G. Gili, 1996

PARSONS, K. The environmental ergonomics survey. In Wilson, J R (Org). Evaluation of Human Work. Third Edition. USA: Taylor \& Francis, 2005.

VILLAROUCO, V. An ergonomic look at the work environment, Proceeding from IEA 09: 17th World Congress on Ergonomics. China: Beijing. 2009.

VILLAROUCO, V. Avaliação Ergonômica do projeto arquitetônico. In: XII Congresso Brasileiro de Ergonomia VI Congresso Latino-Americano de Ergonomia e I Seminário Brasileiro de Acessibilidade Integral. Recife, 2002.

VOORDT, T. JM van der; WEGEN, H. BR van. Architecture in Use: An Introduction to the Programming, Design and Evaluation of Buildings. United Kingdon: Elsevier, 2005. 